\title{
Propofol vs. thiopental in hypotention after GA induction
}

\author{
Bailong $\mathrm{Hu}^{1} \cdot \mathrm{Yi}_{\mathrm{Z}} \mathrm{hhong}^{1} \cdot$ Xiaohua Zou $^{1}$ (D) \\ Received: 2 August 2019 / Accepted: 16 September 2019 / Published online: 24 September 2019 \\ (c) Japanese Society of Anesthesiologists 2019
}

Keywords Thiopental $\cdot$ Hypotension after induction of general anesthesia

To the Editor:

We have read with great interest the recently published article by Hino et al. [1], which compares the incidence of hypotension after induction of general anesthesia (GAIH) between propofol and thiopental in non-cardiac surgery. The author showed that thiopental is more suitable than propofol for avoiding GAIH. However, there are several aspects of this study that need to be clarified and discussed.

As far as we know, preoperative fasting time is one of the risk factors for GAIH and GAIH rates are significantly higher in patients who fasting too long [2]. However, the preoperative fasting times was not clearly described in the method section. This may confuse the interpretation of their findings.

Moreover, Jor et al. [3] found that the GAIH was more likely to occur with the presence of hypertension and diabetes. However, the authors did not describe whether hypertension and diabetes patients were included in this study. Therefore, without providing the above information, we are not convinced that GA induction with thiopental is preferable in elderly patients to avoid hypotension. We believe that this article would be much stronger and useful to readers by addressing the above issues.

\section{Compliance with ethical standards}

Conflicts of interest The authors declare that they have no conflict of interest.

\section{Reference}

1. Hino H, Matsuura T, Kihara Y, Tsujikawa S, Mori T, Nishikawa K. Comparison between hemodynamic effects of propofol and thiopental during general anesthesia induction with remifentanil infusion: a double-blind, age-stratified, randomized study. J Anesth. 2019;33(4):509-15.

2. Yeniay O, Tekgul ZT, Okur O, Koroglu N. Unexpectedly prolonged fasting and its consequences on elderly patients undergoing spinal anesthetics. A prospective observational study. Acta Cirurgica Brasileira. 2019;34(3):e201900309.

3. Jor O, Maca J, Koutna J, Gemrotova M, Vymazal T, Litschmannova M, Sevcik P, Reimer P. Hypotension after induction of general anesthesia: occurrence, risk factors, and therapy. A prospective multicentre observational study. J Anesth. 2018;32(5):673-80.

Publisher's Note Springer Nature remains neutral with regard to jurisdictional claims in published maps and institutional affiliations.

This comment refers to the article available online at https://doi. org/10.1007/s00540-019-02657-x.

Xiaohua Zou

409017612@qq.com

1 Department of Anesthesiology, The Affiliated Hospital of Guizhou Medical University, No. 28 Guiyi Street, Yunyan

District, Guiyang 550004, China 